\title{
Poster Abstracts from the \\ Third International Symposium on Gait and Balance in Multiple Sclerosis
} Selecting the Right Measures

\author{
Saint Louis University • St. Louis, Missouri, USA • October 18 \& 19, 2013 \\ Editor's note: This is a listing of the poster abstract titles, authors, and author affliations. \\ The full abstracts are available on IJMSC's online edition at http:/IIJMSC.org.
}

\section{(1) COMPARISON OF AN INTERMITTENT VS. CONTINUOUS WALKING PROGRAM IN PERSONS WITH MULTIPLE SCLEROSIS USING THE 6 MINUTE WALK TEST: A RANDOMIZED CROSSOVER PILOT STUDY \\ H Karpatkin, S DiCarrado, B Dungan, E Huallpa, J Potrzeba \\ Hunter College, City University of New York, New York, NY}

(2) CONSTRUCT VALIDITY OF THE FUNCTIONAL GAIT ASSESSMENT IN PERSONS WITH MULTIPLE SCLEROSIS

Anette Forsberg, ${ }^{1,2}$ Ylva Nilsagård ${ }^{2,3}$

'Family Medicine Research Centre, Örebro County Council, Örebro, Sweden; ${ }^{2} \mathrm{~S}$ chool of Health and Medical Sciences, Örebro University, Örebro, Sweden; ${ }^{3}$ Centre for Health Care Sciences, Örebro County Council, Örebro, Sweden

(3) IMMEDIATE IMPACT OF A HIP FLEXION ASSIST DEVICE ON SPATIOTEMPORAL PARAMETERS OF GAIT IN INDIVIDUALS WITH MS

Francois Bethoux

Mellen Center for MS Treatment and Research, Cleveland Clinic, Cleveland, $\mathrm{OH}$

(4) STRUCTURAL CONNECTIVITY OF

PROPRIOCEPTIVE NEURAL PATHWAYS IN MS

Brett W. Fling, Fay B. Horak

Department of Neurology, Oregon Health and Science University,

Portland, OR

(5) USE OF INERTIAL SENSORS TO DETECT EFFECTS OF DALFAMPRIDINE ON BALANCE IN PEOPLE WITH MULTIPLE SCLEROSIS

GG Dutta, M Mancini, RI Spain, FB Horak, MH Cameron

Department of Neurology, Oregon Health and Science University,

Portland, OR

(6) EFFECT OF A SERVICE DOG ON AMBULATION IN MS INDIVIDUALS WITH GAIT DYSFUNCTION

Cecilie Fjeldstad, Gabriel Pardo

Oklahoma Medical Research Foundation, MS Center of Excellence, Oklahoma City, OK

\section{(7) DETECTING CHANGES IN GAIT CHARACTERISTICS DURING A SIX-MINUTE WALK USING WIRELESS TECHNOLOGY IN MS SUBJECTS \\ Matthew Engelhard,' Stephen D. Patek, Shanshan Chen, ${ }^{2}$ John Lach, ${ }^{2}$ Rebecca Yeamans, ${ }^{3}$ Myla D. Goldman ${ }^{3}$ \\ 'Department of Systems and Information Engineering, University of Virginia, Charlottesville, VA; ${ }^{2}$ Charles L. Brown Department of Electrical and Computer Engineering, University of Virginia, Charlottesville, VA; ${ }^{3}$ Department of Neurology, University of Virginia, Charlottesville, VA}

(8) SYNERGISTIC EFFECT OF IMPAIRED VIBRATION AND LOWER LIMB KINETICS CONTRIBUTING TO GAIT AND BALANCE LIMITATIONS IN MULTIPLE SCLEROSIS

EC Held Bradford,' $R T$ Taismith, ${ }^{2}$ JM Wagner ${ }^{3}$

'Department of Neurology, Saint Louis University, St. Louis, MO; ${ }^{2}$ Department of Neurology, Washington University in St. Louis, St. Louis, MO; ${ }^{3}$ Department of Physical Therapy and Athletic Training, Saint Louis University, St. Louis, MO

(9) PHYSIOLOGICAL FALL RISK AND DUAL TASK COST OF WALKING

DA Wajda, RW Motl, JJ Sosnoff

Department of Kinesiology and Community Health, University of Illinois at Urbana-Champaign, Urbana, IL

(10) ACCELEROMETRY TO MEASURE POSTURAL SWAY IN PERSONS WITH MULTIPLE SCLEROSIS AGREES WITH GOLD STANDARD MEASURES Jessie M. Huisinga, ${ }^{1}$ Martina Mancini, ${ }^{2}$ Rebecca Spain, ${ }^{2,3}$ Fay B. Horak ${ }^{2}$ University of Kansas Medical Center, Kansas City, KS; ${ }^{2}$ Oregon Health and Science University, Portland, OR; ${ }^{3}$ Neurology Service and MS Center of Excellence-West, Portland VA Medical Center, Portland, OR

( 11 ) CONCURRENT VALIDITY OF THE PATIENTSPECIFIC FUNCTIONAL SCALE AND THE TIMED 25 FOOT WALK TEST IN PEOPLE WITH MULTIPLE SCLEROSIS

Mark M. Mañago, ${ }^{1,2}$ Jeffrey R. Hebert ${ }^{2}$

'University of Colorado Hospital, Aurora, CO; 2 Physical Therapy Program, University of Colorado Denver, Anschutz Medical Campus, Aurora, CO 


\section{(12) COHERENCE ANALYSIS REVEALS}

\section{ALTERED POSTURAL CONTROL DURING}

\section{STANDING IN PERSONS WITH MULTIPLE}

\section{SCLEROSIS}

FB Horak, ${ }^{1} \mathrm{JM}$ Huisinga, ${ }^{2}$ M Mancini ${ }^{1}$

'Oregon Health and Science University, Portland, OR; ${ }^{2}$ University of Kansas

Medical Center, Kansas City, KS

\section{(13) BALANCE-EXERCISE PROGRAMME REDUCED}

\section{FALLS IN PEOPLE WITH MS}

Y Nilsagård, ${ }^{1,2} \mathrm{~L}$ von Koch, ${ }^{3} \mathrm{~A}$ Forsberg ${ }^{2,4}$

'Centre for Health Care Sciences, Örebro County Council, Örebro, Sweden;

${ }^{2} S$ chool of Health and Medical Sciences, Örebro University, Örebro, Sweden;

${ }^{3}$ Division of Neurology, Department of Clinical Neuroscience, Karolinska Institutet, Stockholm, Sweden; ${ }^{4}$ Family Medicine Research Centre, Örebro County Council, Örebro, Sweden
(14) EFFECT OF DALFAMPRIDINE ON GAIT AND BALANCE IN PATIENTS WITH MULTIPLE SCLEROSIS: THE STEADY STUDY

Gabriel Pardo, ${ }^{1}$ Cecilie Fjeldstad, ${ }^{1}$ Gustavo Suárez, ${ }^{2}$ Michael Klingler, ${ }^{2}$ Herbert R. Henney III, ${ }^{2}$ Adrian L. Rabinowicz ${ }^{2}$

'Oklahoma Medical Research Foundation, MS Center of Excellence, Oklahoma City, OK; ${ }^{2}$ Acorda Therapeutics, Inc, Ardsley, NY

(15) PHYSIOLOGICAL FACTORS OF GAIT VARIABILITY IN PERSONS WITH MULTIPLE SCLEROSIS

J Sung, Y Moon, DA Wajda, S Balantrapu, RW Motl, JJ Sosnoff

Department of Kinesiology and Community Health, University of Illinois at Urbana-Champaign, Urbana, IL

(16) CENTER OF PRESSURE TRAJECTORY OF FOOT FALLS IN MULTIPLE SCLEROSIS

Y Moon, DA Waida, J Sung, RW Motl, JJ Sosnoff

Department of Kinesiology and Community Health, University of Illinois at Urbana-Champaign, Urbana, IL

\section{Peer Reviewers}

The editorial staff of the International Journal of MS Care acknowledges and thanks all of our 2013 peer reviewers. We appreciate your support and professional expertise. Through your dedication, we are able to achieve our mission of providing a high-quality peer-reviewed publication.

Angie Andreoli

Elizabeth Auld

Deborah Backus

Barbara Baker

Khurram Bashir

Jill Beavin

Mary Bell

Cathy Benbow

Ralph Benedict

Francois Bethoux

Francesca Bevilacqua

Joyce Binford

A. Bogosian

Jennifer Boyd

Eileen Boylan

Kathleen Brandfass

Bruno Brochet

Lacey Bromley

Cara Brown

Lisa Brown

Theodore Brown

Robert Buchanan

Cara Burdette

Christina Burke

Theresa Burke

Kim Calder

Michelle Cameron

Christina Caon

Sherry Card

Jonathan Carter

Patricia Casey

Daniela Cavalcante

James Cavanaugh
Mirela Cerghet

Michael Chancellor

Toni Chiara

Megan Clancy

Susan Conroy

Devon Conway

Jill Conway

Susan Coote

Lois Copperman

Margarita Corry

Peggy Crawford

Linda Csiza

William Culpepper

Mary Dallas

H. Diener

Kathy Dieruf

Christy Dittmar

Elizabeth Dobie

Kelli Doern

Ron Duran

Constance Easterling

Keith Edwards

Dawn Ehde

Robert Fallis

Greg Farmer

Mary Filipi

Allison Fine

Marcia Finlayson

Peter Flachenecker

Frederick Foley

Peter Foley

Sue Forwell

Mark Freedman
Kathleen Fuchs

Eduard Gappmaier

Martha Glisky

Shirley Groer (Fitzgerald)

Elizabeth Gromisch

Paivi Hamalainen

Kathleen Healey

Chris Heesen

Rock Heyman

Elizabeth Holland

Jessie Huisinga

Dina Jacobs

Mary Jezewski

Rosalind Kalb

Mary Karpinski

Zaza Katsarava

Michael Kaufman

Margaret Keller

Pat Kennedy

Wilma Koopman

Yvonne Learmonth

Pat Leuschen

V. Limmroth

Albert Lo

Diana Logan

Alison Mackay

Sangeeta Mahajan

Heidi Maloni

James Marriott

Virgil Mathiowetz

Kathleen Matuska

Lori Mayer

Nancy Mayo
Megan McDaniel

Patricia Messier

Deborah Miller

Courtenay Moore

Marie Moore

Sarah Morrow

Robert Motl

Marie Namey

Alexander Ng

Vanessa Noonan

Patricia Odom

Shirley O'Leary

Brant Oliver

Timothy O'Maley

Jean-Christophe Ouallet

Mary Owen

Karen Paraska

Scott Patten

Eugenio Peluso

C. Piwko

Matthew Plow

Katharine Preissner

Norman Putzki

Alexander Rae-Grant

John Ratchford

David Rintell

Priscilla Russo

Matthew Sacco

Toni Saldana-King

Carrie Sammarco

Kathryn San Martino

Carol Saunders

Eileen Scheid
Judith Scheman

Angela Seevers

Anjali Shah

Jennifer Sippel

Christine Smith

Matthew Sorenson

Amy Sullivan

Chad Swank

Jenifer Thomas

Peter Thomas

Mary Thompson

Andrea Todd

Sara Tompkins

Helen Tremlett

Aaron Turner

M. Turner

Karen Turpin

Gray Vargas

Aimee Verrall

Mary Ellen Vore

Reza Vosoughi

Joanne Wagner

Lisa Walker

Tracy Walker

Megan Weigel

Shawna Weigel

Mitzi Williams

Mary Alissa Willis

Joshua Wilt

Roberta Winter

Heather Wishart

Judy Wollin

Gael Yonnet

Kathy Zackowski 